\title{
The emergence of oseltamivir-resistant pandemic influenza A(H1N1) 2009 virus amongst hospitalised immunocompromised patients in Scotland, November- December, 2009
}

H Harvala (heli.harvala@luht.scot.nhs.uk) ${ }^{1}$, R Gunson², P Simmonds ${ }^{3}$, A Hardie ${ }^{1}$, S Bennett ${ }^{2}$, F Scott ${ }^{4}$, H Roddie R $^{4}$ J McKnight 5 , T Walsh ${ }^{6}$, D Rowney7, A Clark7,8, J Bremner ${ }^{1}$, C Aitken ${ }^{2}$, K Templeton ${ }^{1}$

1. Specialist Virology Centre, Royal Infirmary of Edinburgh, Edinburgh, United Kingdom

2. West of Scotland Specialist Virology Centre, Glasgow, United Kingdom

3. Centre for Infectious Diseases, University of Edinburgh, Edinburgh, United Kingdom

4. Department of Haematology, Western General Hospital, Edinburgh, United Kingdom

5. Metabolic Unit, Western General Hospital, Edinburgh, United Kingdom

6. Intensive Therapy Unit, Royal Infirmary of Edinburgh, Edinburgh, United Kingdom

7. Department of Paediatric Haematology, Royal Hospital for Sick Children, Glasgow, United Kingdom

8. Bone Marrow Transplant Unit, Gartnaval General Hospital, Gartnavel General Hospital, Glasgow, United Kingdom

Citation style for this article:

Citation style for this article: Harvala H, Gunson R, Simmonds P, Hardie A, Bennett S, Scott F, Roddie H, McKnight J, Walsh T, Rowney D, Clark A, Bremner J, Aitken C, Templeton K. The emergence of oseltamivir-resistant pandemic influenza A(H1N1) 2009 virus amongst hospitalised immunocompromised patients in Scotland, November-December, 2009. Euro Surveill. 2010;15(14):pii=19536. Available online: http://www.eurosurveillance.org/ViewArticle.aspx?Articleld=19536

To investigate the frequency of oseltamivir resistance in circulating strains of the 2009 influenza $\mathrm{A}\left(\mathrm{H}_{1} \mathrm{~N}_{1}\right)$ pandemic virus in Scotland, 1,802 samples from 1,608 infected hospitalised patients were screened by the H275Y discriminatory RT-PCR. Among these, we identified 10 patients who developed the $\mathrm{H}_{275} \mathrm{Y}$ mutation. All of them were immunocompromised and were under treatment or had been treated previously with oseltamivir.

\section{Introduction}

The 2009 influenza $A\left(\mathrm{H}_{1} \mathrm{~N}_{1}\right)$ pandemic virus emerged in Mexico in March 2009 and spread globally and uncontrollably during the following months. The World Health Organization (WHO) declared a pandemic caused by this virus on 11 June 2009. Since the first case diagnosed in Scotland in May 2009, a total of 6,450 laboratory confirmed 2009 pandemic virus infections leading to 62 deaths had been diagnosed in Scotland by 3 January 2010.

Initial testing of the 2009 pandemic virus found it susceptible to neuraminidase inhibitors, oseltamivir and zanamivir, but resistant to amantadine [1]. Oseltamivir has been used extensively for chemoprophylaxis and treatment for 2009 pandemic virus and the first sporadic cases of oseltamivir-resistant 2009 pandemic virus infection were reported at the end of July 2009 [2]. The emergence of oseltamivir-resistant 2009 pandemic virus remains a major concern, since widespread oseltamivir resistance has been observed in seasonal $\mathrm{H}_{1} \mathrm{~N}_{1}$ viruses recently [3-5]. The emergence of oseltamivir-resistant seasonal influenza $A\left(\mathrm{H}_{1} \mathrm{~N}_{1}\right)$ viruses was first noted in Norway 2007 [3], and these resistant viruses have since evolved into the dominant influenza $\mathrm{A}\left(\mathrm{H}_{1} \mathrm{~N}_{1}\right)$ seasonal viruses circulating in humans.

Resistance to oseltamivir in influenza $\mathrm{A}\left(\mathrm{H}_{1} \mathrm{~N}_{1}\right)$ viruses caused by a histidine to tyrosine mutation at residue 275 of the neuraminidase protein $\left(\mathrm{H}_{275} \mathrm{Y}\right)$ was observed both in vitro and in vivo $[6,7]$. Very recently, this mutation has also been detected in in oseltamivirresistant 2009 pandemic viruses in China, the United States (US), Vietnam and Canada [8-11]. Although there is no evidence so far that these viruses might have transmitted beyond close contact between cases, two clusters of immunocompromised hospitalised patients infected with the 2009 pandemic virus virus have been detected in Wales, United Kingdom (UK) [12] and North Carolina, US [13]. The possible spread of oseltamivirresistant 2009 pandemic virus is alarming from the public health point of view because of consequences for treatment and prophylaxis of 2009 pandemic influenza. We report the emergence of oseltamivir-resistant 2009 pandemic virus strains in immunocompromised patients in Scotland.

\section{Study methods and results}

To investigate the frequency of oseltamivir resistance in circulating strains of 2009 pandemic virus, the $\mathrm{H}_{275} \mathrm{Y}$ discriminatory reverse transcription RT-PCR was used to screen 1,802 samples from all 1,608 infected hospitalised patients in Edinburgh and Glasgow between 1 November and 31 December 2009 (Table). In addition, 32 patients with available samples from the time of diagnosis and post treatment with oseltamivir were analysed and clinical features recorded. 
The applied method can detect as little as $5 \%$ of oseltamivir-resistant 2009 pandemic virus in mixed virus populations [14]. Detection of the $\mathrm{H}_{275} \mathrm{Y}$ mutation was confirmed by pyrosequencing in the Health Protection Agency's Centre for Infections in London, the United Kingdom. Full-length sequencing of the neuraminidase gene was performed. Patients files with their medical history and virological investigations were reviewed for all patients with evidence for the $\mathrm{H} 275 \mathrm{Y}$ mutation.

Sequences amplified from all pandemic influenza virus samples collected pre-treatment were wild type at position 275 in the neuraminidase gene, providing no evidence for circulation of oseltamivir-resistant 2009 pandemic virus in the area. However, 10 patients in our study developed the $\mathrm{H}_{275} \mathrm{Y}$ mutation during or after oseltamivir therapy.

Full-length sequences of the neuraminidase gene did not reveal any other mutations than the $\mathrm{H}$ to $\mathrm{Y}$ change at position 275 in our patients. In two of them, resistant virus persisted for at least 25 to 40 days following cessation of treatment, suggesting oseltamivir-resistant 2009 pandemic viruses were not compromised in their replication ability.

All patients who developed oseltamivir resistance were immunocompromised, eight of them with haematological malignancy The frequency of resistance-development in patients with 2009 pandemic influenza treated with oseltamivir was assessed further by analysing data for 32 patients from Edinburgh of whom 10 were immunocompromised and 22 non-immunocompromised. Antiviral-resistant viruses were detected in five of the 10 immunocompromised patients, all of whom had been treated with oseltamivir. In comparison, none of the non-immunocompromised patients developed resistance during or after oseltamivir-treatment (o/22 versus $5 / 10, p=0.0012$, Fisher's exact test).

\section{Conclusions}

Systematic follow-up of patients hospitalised with 2009 pandemic influenza and treated with oseltamivir and large-scale screening of untreated hospitalised 2009 pandemic influenza patients showed an association between the appearance of the $\mathrm{H} 275 \mathrm{Y}$ mutation and oseltamivir treatment. In our study population, we found no evidence for the spontaneous emergence of resistance in untreated patients. This contrasts with very recent findings of resistance in a small number of Chinese and Vietnamese subjects who had not received oseltamivir prophylaxis or treatment $[8,10]$. These results have been interpreted as showing that spontaneous mutation can occur either before or during infection, or that there is transmission of oseltamivir-resistant virus in some geographical regions.

In our study, oseltamivir resistance development was restricted to immunocompromised subjects, consistent with the previous descriptive study of the isolation of oseltamivir-resistant 2009 pandemic virus from two severely immunosuppressed patients with haematologic malignancy [13]. In both of them, persistent viral shedding led to prolonged use of oseltamivir and the subsequent development of oseltamivir-resistant 2009 pandemic virus variants. The prolonged period of infection (up to 61 days in our study) and large population sizes associated with poorly controlled virus replication favoured the development of resistance. This could provide evidence that emergence of resistance can result from selection of mutants from genetically diverse quasispecies within the infected individual. Despite the small study numbers, the result that 5 of 10 of immunocompromised patients treated with oseltamivir developed drug resistance could have implications for further management of 2009 pandemic virus infections.

An additional factor influencing resistance development is the dosage of antivirals administered. In previous studies, oseltamivir-resistant 2009 pandemic virus strains were detected in patients who became infected during oseltamivir chemoprophylaxis $[2,9,11]$. In these cases, subtherapeutic levels of oseltamivir may have only partially inhibited viral replication, facilitating the emergence of resistance. All our study subjects received the adequate and recommended treatment doses of oseltamivir. However, the efficacy of recommended oseltamivir treatment in immunocompromised

\section{TABLE}

$\mathrm{H} 275 \mathrm{Y}$ mutation resistance testing of confirmed 2009 pandemic influenza A(H1N1) virus samples from hospitalised patients, Scotland, November 2009-December 2009 ( $n=1,802$ samples)

\begin{tabular}{|c|c|c|c|}
\hline & Edinburgh & Glasgow & Total \\
\hline Number of samples tested for 2009 pandemic virus & 2,507 & 6,300 & 8,807 \\
\hline Number of 2009 pandemic virus positive samples & 423 & 1,379 & 1,802 \\
\hline Number of 2009 pandemic virus positive patients & 352 & 1,256 & 1,608 \\
\hline Number of $\mathrm{H}_{275} \mathrm{Y}$ positive patients & 5 & 5 & 10 \\
\hline Time period & 1.11-31.12.2009 & \multicolumn{2}{|c|}{ 6.11-31.12.2009 } \\
\hline Method for $\mathrm{H}_{275}$ Y screening & $\begin{array}{l}\text { All } 2009 \text { pandemic virus positive } \\
\text { samples tested with H275Y RT-PCR }\end{array}$ & \multicolumn{2}{|c|}{$\begin{array}{l}\text { All respiratory samples tested with } \mathrm{H} 275 \mathrm{Y} \text { with } \\
\text { multiplex RT-PCR (2009 pandemic virus, FluA } \\
\text { and } \mathrm{H} 275 \mathrm{Y} \text { ) }\end{array}$} \\
\hline
\end{tabular}

FluA: influenza virus type A; RT-PCR: reverse transcription-polymerase chain reaction 
patients has not been established and further studies are needed in this respect.

Finally, the emergence of resistant forms of influenza viruses depends on the relative fitness of drugresistant strains compared to wild type virus. A recent study showed that a seasonal influenza $A\left(\mathrm{H}_{1} \mathrm{~N}_{1}\right)$ virus isolated in Canada with $\mathrm{H}_{275} \mathrm{Y}$ mutation had at least comparable viral fitness both in vitro and in ferrets relative to that of a closely related wild type strain [15]. Although we were unable to assess the replication fitness or infectivity directly, the appearance of oseltamivir-resistant variants and replacement of the original wild type strains eight to 12 days after the end of treatment in two individuals could hint towards a possible fitness advantage of oseltamivir-resistant viruses.

The majority of circulating 2009 pandemic virus strains worldwide has remained susceptible to oseltamivir [2]. However, the recent spontaneous emergence of oseltamivir-resistant seasonal influenza $\mathrm{A}\left(\mathrm{H}_{1} \mathrm{~N}_{1}\right)$ virus $[4,5]$ shows that in theory there could be the possibility that oseltamivir-resistant 2009 pandemic virus may also become dominant during the next influenza season.

The induction of resistance in immunosuppressed patients seen in our study highlights the importance of close monitoring and containment of this group during therapy. All possible interventions should be adopted to prevent the emergence of oseltamivir-resistant 2009 pandemic virus strains, including the vaccination of immunocompromised individuals and their household contacts with the pandemic influenza vaccine.
10. Le QM, Wertheim HF, Tran ND, van Doorn HR, Nguyen TH, Horby $\mathrm{P}$; Vietnam $\mathrm{H}_{1} \mathrm{~N}_{1}$ Investigation Team. A community cluster of oseltamivir-resistant cases of $2009 \mathrm{H}_{1} \mathrm{~N}_{1}$ influenza. N Engl J Med. 2010;362(1):86-7.

11. Baz M, Abed Y, Papenburg J, Bouhy X, Hamelin M, Boivin G. Emergence of oseltamivir-resistant pandemic $\mathrm{H}_{1} \mathrm{~N}_{1}$ virus during prophylaxis. N Engl J Med. 2009;361(23):2296-7.

12. World Health Organization. Pandemic ( $\left.\mathrm{H}_{1} \mathrm{~N}_{1}\right)$ 2009: briefing note 18, Geneva, Switzerland: World Health Organisation; 2009. http://www.who.int/csr/disease/swineflu/notes/ briefing_20091202/en/index.html.

13. Centers for Disease Control and Prevention. Oseltamivirresistant novel influenza $A\left(\mathrm{H}_{1} \mathrm{~N}_{1}\right)$ virus infection in two immunosuppressed patients, August 2009. MMWR Morb Mortal Wkly Rep 2009;58(32):893-6.

14. van der Vries E, Jonges M, Herfst S, Maaskant J, van der Linden A, Gulgemeester J, et al. Evaluation of a rapid molecular algorithm for detection of pandemic influenza $A\left(\mathrm{H}_{1} \mathrm{~N}_{1}\right) 2009$ virus and screening for a key oseltamivir resistance $\left(\mathrm{H}_{275} \mathrm{Y}\right)$ substitution in neuraminidase. J Clin Virol. 2010;47(1):34-7.

15. Baz M, Abed Y, Simon P, Hamelin M, Boivin G. Effect of the neuraminidase mutation $\mathrm{H}_{274} \mathrm{Y}$ conferring resistance to oseltamivir on the replicative capacity and virulence of old and recent human influenza $A\left(\mathrm{H}_{1} \mathrm{~N}_{1}\right)$ viruses. J Infect Dis. 2010;201(5):740-115.

\section{References}

1. Centers for Disease Control and Prevention. Drug susceptibility of swine-origin influenza $A\left(\mathrm{H}_{1} \mathrm{~N}_{1}\right)$ viruses, April 2009. MMWR Morb Mortal Wkly Rep. 2009;58(16):433-5.

2. World Health Organization. Pandemic $\left(\mathrm{H}_{1} \mathrm{~N}_{1}\right)$ 2009: update 6o. Geneva, Switzerland: World Health Organization; 2009. Available from: http://www.who.int/csr/don/2009_08 04/en/ index.html.

3. Hauge SH, Dudman S, Borgen K, Lackenby A, Hungnes O. Oseltamivir-resistant influenza viruses $\mathrm{A}\left(\mathrm{H}_{1} \mathrm{~N}_{1}\right)$, Norway, 200708. Emerg Infect Dis. 2009;15(2):155-62.

4. Meijer A, Lackenby A, Hungnes 0 , Lina B, van der Werf $\mathrm{S}$, Schweiger B, et al. Oseltamivir-resistant influenza virus $A\left(\mathrm{H}_{1} \mathrm{~N}_{1}\right)$, Europe, 2007-08 season. Emerg Infect Dis. 2009;15(4):552-60.

5. Dharan NJ, Gubareva LV, Meyer JJ, Okomo-Adhiambo M, McClinton RC, Marshall SA, et al. Infections with oseltamivirresistant influenza $A\left(\mathrm{H}_{1} \mathrm{~N}_{1}\right)$ virus in the United States. JAMA. 2009;301(10):1034-41.

6. Wang MZ, Tai CY, Mendel DB. Mechanism by which mutations at His274 alter sensitivity of influenza $A$ virus $\mathrm{N}_{1}$ neuraminidase to oseltamivir carboxylate and zanamivir. Antimicrob Agents Chemother. 2002;46(12):3809-16.

7. McKimm-Breschkin J, Trivedi T, Hampson A, Hay A, Klimov $A$, Tashiro $M$, et al. Neuraminidase sequence analysis and susceptibilities of influenza virus clinical isolates to zanamivir and oseltamivir. Antimicrob Agents Chemother. 2003;47(7):2264-72.

8. Chen H, Cheung CL, Tai H, Zhao P, Chan JF, Cheng VC et al. Oseltamivir-resistant influenza A pandemic (H1N1) 2009 virus, Hong Kong, China. Emerg Infect Dis. 2009;15(12):1970-2.

9. Centers for Disease Control and Prevention. Oseltamivir resistant 2009 pandemic influenza $A\left(\mathrm{H}_{1} \mathrm{~N}_{1}\right)$ virus infection in two summer campers receiving prophylaxis, September 2009. MMWR Morb Mortal Wkly Rep. 2009;58(35):969-72. 